\title{
Development of a community based management protocol for diffuse pollution control in agro-rural watersheds
}

\author{
Sibekile Mtetwa* and C Frederik Schutte \\ Department of Chemical Engineering, University of Pretoria, South Africa
}

\begin{abstract}
Water quality management is a very serious problem in the rural areas of developing countries. The main contribution to pollution of water sources in these areas is from diffuse sources, notably from subsistence farming. It is evident that water quality management would only be effective by changing the practices that contribute to diffuse pollution. This paper is based on a project that employed a systematic approach to involve and mobilise rural communities in water quality control programmes. The aim of the project is to develop methodologies that could be employed in rural areas to control the generation of diffuse pollution. The investigation is based on a pilot project in an agro-rural sub-watershed in a developing country. Stakeholder participation and technical control options were concurrently investigated in the development of a community based diffuse pollution management protocol that could be applied in rural areas with poorly developed local government structures.
\end{abstract}

\section{Introduction}

The implementation of pollution control measures and water quality management is extremely difficult in the rural areas of developing countries (Hoffman, 1994). The main contribution to pollution of water resources in these areas is from diffuse sources, notably from subsistence farming. Farming practices that contribute to water pollution include overgrazing, removal of trees and bushes for firewood, ploughing, tilling and cultivating on stream- and river banks and in wetlands, poor fertilizing practices, etc. It is evident that water quality management would only be effective by changing the practices that contribute to diffuse pollution.

The management of water resources in most Southern African countries has entered an exciting new phase. The respective governments are placing considerable emphasis on community involvement in resources management. This is because the current water quality problems have proved to be beyond the scope of technological solutions alone and require the involvement of all stakeholders including rural communities (Martin, 1991). The situation is even worse in terms of diffuse pollution because it is difficult to identify, isolate or control (Hoffman, 1994).

This paper is based on a pilot project in the Muda river catchment in Zimbabwe, aimed at developing a methodology for the management of diffuse pollution from an agro-rural watershed. It follows on an earlier paper by the same authors in which details of the catchment, farming practices and pollution loads are given (Mtetwa and Schutte, 2002). In this paper the focus is on the development of the protocol for diffuse pollution management.

The availability of methodologies for water quality management in rural areas has become very important and urgent in many countries in southern Africa where land reform processes are increasingly implemented and accelerated. Land reform has already resulted in large increases in the numbers of subsistence farmers

\footnotetext{
* To whom all correspondence should be addressed. Current address: Zimbabwe National Water Authority, Water Quality Section, PO Box CY 617, Causeway, Harare, Zimbabwe. 䱾+2634 793139; e-mail: mtetwa@utande.co.zw Received 4 April 2002; accepted in revised form 16 October 2002.
}

and in land area being used for this purpose. Urgent measures are therefore required to prevent or limit the potential negative effects of subsistence farming on the environment and specifically on water resources.

The methodology to manage and control diffuse pollution from rural agricultural activities was developed from the practical experience gained in the Muda project. The proposed methodology is based on lessons learnt during the project, on problems experienced and practical measures to overcome such problems. The basic premise has been to introduce community-based water management through environmentally sustainable agricultural practices.

In developed societies local government structures can be used both for service and social requirements delivery. Public sector funding and discharge permit trading are available for diffuse pollution management (Novotny, 1999). However for less developed societies local government structures are almost non-existent and people have to rely on community-based management for services (Van der Voorden, 2002). Community-based management approaches have been applied for operation, maintenance and management of water and sanitation systems where the communities derive direct and immediate benefits from such services. However, the benefits from water quality management are not obvious and communities therefore are not willing to invest therein (Schoeman, 1997).

A diffuse pollution management protocol was developed in an interactive manner with the community. A systems analysis approach was followed. This is a relatively complex process especially in a developing semi-arid region where resources are scarce and water quality is not a priority. Further complicating factors included volatile political activities that developed during the course of the project, a serious economic downturn and varying climatic conditions of very high rainfall during the first phases followed by a drought period.

It was accepted at the inception of the project that a technical approach and technical solutions would not be appropriate for the circumstances in a rural area such as the Muda catchment. It was decided that the technical aspects would be handled by the project team mainly to monitor the situation with respect to water quality, runoff, and stream flow. The focus of the project would be on the socio-economic aspects of creating awareness with the people of 
their environment and specifically water quality and the effects thereof on their quality of life and on agricultural production.

\section{Methodology}

It was accepted from the inception of the project that it would be difficult to reach clear conclusions about the outcomes achieved due to the fact that there are many uncontrollable aspects that could affect findings and outcomes. Furthermore, the sustainability of changes in agricultural and other practices and the effects thereof on water quality could only be evaluated over the long term ( 5 - 10 years). This means that the project will have to continue for a much longer term than the four years that it has been running up to this stage. Outcomes must therefore be regarded as interim findings that would only be confirmed over a much longer term.

The basic options for managing water quality include pollution prevention by instituting technology changes for clean technology, reduction of pollutants at source and along the delivery pathways, and collection and treatment of waste effluents. In the case of diffuse pollution the only option is the reduction of wastes at source and along the delivery pathways. This was achieved by creating a common framework for communication and interaction with the community and the facilitators. The interactions resulted in awareness creation, empowerment and changes in agricultural and environmental practices. The net effects of these changes were monitored through monitoring of fertilizer application rates, observations of areas cultivated and water quality.

The approach taken applies the three classic concepts of community development: "self help", "felt needs" and "participation" so as to give the community a sense of ownership of the programme (Van Voorden, 2002). In addition, a collaborative approach was taken and officers from the Agricultural extension services and Natural Resources Board of Zimbabwe were incorporated into the project team.

\section{Social sciences aspects}

The primary social sciences aspects in the approach included the institution of a participatory framework, establishing a knowledge base, empowering individuals to be masters of their own destiny and ultimately changing their mindset for better natural resources stewardship.

A number of initial awareness campaigns were undertaken in order for the community to buy-in to the water quality ideas. When the community realised that there was a real need to reduce and possibly reverse degradation of the natural resources in their areas, the principle of "felt needs" had been established and the rest of the mechanisms then centred on "self help" and "participation". The initial stage was to assess the situation on the ground without influencing the behaviour of the communities, and then afterwards develop programmes to influence their behaviour. The success of the programme was measured by concurrently monitoring water quality and the quality of the environment together with agricultural yields. Water quality monitoring is a relatively simple matter once a monitoring system is established, but monitoring of the other indicators is rather difficult and one has to rely on figures provided by the farmers and sales of fertilizers and personal observations.

The study was initiated in 1998 and in the first year the communal farmers were left to conduct their farming activities in the usual manner whilst fertiliser application rates were recorded and the effects of their activities on the environment were studied by establishing a water quality monitoring programme.

In the second and subsequent years the activities of the communal farmers were influenced by conducting a series of meetings at ward level throughout the Muda catchment. In 1999 ten meetings were held and at one meeting a record 300 villagers attended. In the subsequent years six ward level meetings were conducted each year and the number of attendants was limited to fifty representatives per ward, mostly the village heads.

The meetings consisted of plenary presentations by the project team and community members, brainstorming, practical field demonstrations and question and answer sessions. The areas covered included:

- Proper agricultural land management

- Proper citing of gardens to avoid stream bank cultivation

- Reduction of pollutant flushes by correct application of fertilizers and biocides,

- Protection of grazing, wetlands and forest lands.

The aim was to influence the behaviour of the community at the source of pollution in order to limit the generation of pollutants. The community was encouraged to actively take part in decisions affecting their watershed. They interactively explored alternative policies for management of the watershed without necessarily implementing new technologies but adapting what they had and managing it properly.

To stimulate interest the participants were presented with small prizes such as T-shirts with water quality messages. A conservation competition was organised in which the participants had to apply in practice what they had learnt in the programme. The farmers of the best-conserved lands were presented with prizes. This raised the communal farmers' interest in the project and was an incentive for them to apply their newly acquired knowledge.

\section{Natural sciences aspects}

Very little water quality information is available in areas such as the Muda catchment. Considerable effort is therefore required to collect data for any meaningful decision- making and conclusions. In order to carry out this project a water quality monitoring system had to be implemented. The programme entailed sampling and analyses of water samples over a four-year period. It also included surveys on fertiliser, manure and biocide application rates, collection of meteorological data, derivation of hydrological data such as flows by using the ACRU model and analysing all the generated data using various tools like Geographical Information Systems (GIS). The monitoring systems were established with the full involvement of the community who assisted in sample site selection and data collection.

\section{The systems model}

Diffuse pollution control has been tackled from various angles. Although the development and use of computer simulations are key aspects in the formulation of decision-making tools, real world physical models and knowledge base approaches have been found to be more effective tools in influencing behaviour in rural communities (Ongley, 1998). In the assessment of diffuse pollution mathematical models play a key role but their appropriateness and the importance of other socio-economic factors like cost and local knowledge have to be taken into account. In this study the simulations were only used as a means to an end, whilst the focus was on the development of a management methodology.

A simple systems model was developed from the village level deliberations with the community and was used in the development 


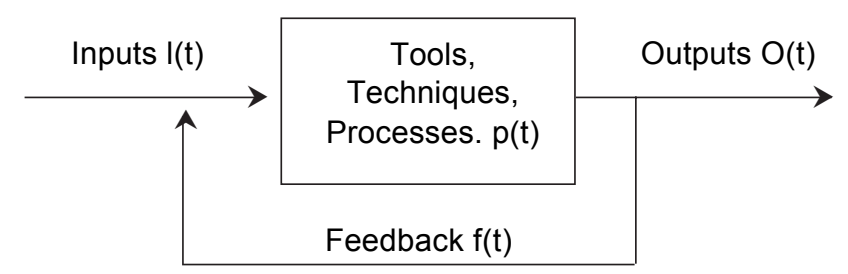

Figure 1

The systems model (adapted from Wright, 2000)

\begin{tabular}{|c|c|c|c|}
\hline \multicolumn{4}{|c|}{$\begin{array}{l}\text { TABLE } 1 \\
\text { A simple systems model for controlling diffuse pollution }\end{array}$} \\
\hline Inputs & Processes & Outputs & Feedback \\
\hline $\begin{array}{l}\text { Water quality } \\
\text { objectives } \\
\text { - } \begin{array}{l}\text { Public and political } \\
\text { support }\end{array} \\
\text { - Consultative } \\
\text { meetings } \\
\text { Water quality } \\
\text { monitoring } \\
\text { Incentives for the } \\
\text { community to } \\
\text { minimise water } \\
\text { pollution }\end{array}$ & $\begin{array}{l}\text { Erecting of contour } \\
\text { ridges } \\
\text { - } \quad \text { Establishment of } \\
\text { grass strips } \\
\text { - } \begin{array}{l}\text { More efficient use } \\
\text { of fertiliser }\end{array} \\
\text { - Alternatives to } \\
\text { biocides } \\
\text { - } \begin{array}{l}\text { Conservation of } \\
\text { natural resources }\end{array}\end{array}$ & 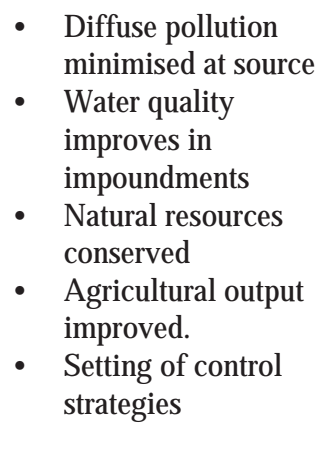 & $\begin{array}{l}\text { Determination of } \\
\text { effectiveness of } \\
\text { processes } \\
\text { Alter inputs to } \\
\text { attain specific } \\
\text { goals }\end{array}$ \\
\hline
\end{tabular}

of the methodology. Figure 1 depicts the systems model (Wright 2000), which was used to develop a simple water quality management system (Table 1) on which the diffuse pollution management protocol is based.

\section{Protocol for diffuse pollution management}

The protocol described below was developed as a methodology to control diffuse pollution in a rural developing farming area. It is based on integrated catchment management with a strong emphasis on community based management approaches. This is regarded as essential to ensure sustainable agricultural practices and preservation of water quality in these communities.

A fundamental premise of the protocol is that the implementing agents should limit themselves to facilitating the process and to offering technical, educational and financial assistance. The communities must be encouraged to identify the problems and explore potential solutions with assistance from the facilitators. It is also desirable to operate under a stable political environment. The current situation in Zimbabwe put the project under stress, but the protocol has shown to be useful even under volatile situations, as long as the situation does not degenerated into anarchy.

The protocol is presented as a six-stage plan of action. The following are prerequisites for this type of programme to be successful:

\section{Prerequisites}

- The communities shall be involved in everything concerning the project right from its inception to give them a sense of ownership and responsibility.
- The local leadership structures which includes the local chiefs, local headman, local political figures and elected ward water association members must be respected and accorded their rightful positions:

- Seek their consent for events like meetings and workshops.

- Encourage them either to fully participate or empower others to do so.

- Respect cultural values and build them into the conservation programmes.

- Develop clear visions and objectives with the communities from the introduction of the programme and develop a common understanding of the goals.

\section{Stage 1: Establishment of structures}

Under Zimbabwe's reform of the water sector, water is managed at catchment level and this has prompted the formation of stakeholder groupings and catchment councils. The Catchment Councils consist of three tiers, i.e. the Ward Water Associations, Sub-catchment Boards and Catchment Boards. They function on the basis of involving all water users in the planning, implementation and management of the water resources including catchment protection and development. The Ward Water Associations are at village level, the Sub-catchment Boards cover sub-catchments and the Catchment Boards cover the major catchments of the country.

In terms of diffuse pollution management, stakeholder groupings serve to guide and keep the process on track. The following factors are important in setting up the stakeholder structures:

- Identify the communities and specific stakeholder groups that must form part of the project to achieve improved management of water resources in the catchment and/or sub catchment. 
- Establish suitable structures for communication with the community at large and with specific stakeholder groups.

- Establish procedures for communication, for obtaining approvals for actions, and for reporting back.

- Develop programmes to encourage people to participate in activities. Initial incentives of providing lunches and attendance rewards can be used, but the aim should be to stimulate voluntary action.

\section{Stage 2: Recording of baseline conditions}

The implementing agent must carry out surveys to establish baseline information that is required for measuring progress once the project is implemented. The baseline information must be collected over a period of at least one year but preferably two years. During this period the communal farmers must be allowed to do their business as usual without any influence from the implementing agent. The following baseline conditions must be recorded:

- Collection and assessment of available topographical, geological and soil information.

- Water quality monitoring at strategic points in order to build up a data basis.

- Assessment of farming practices, specifically determination of fertilizer and farm manure application rates and crop yields.

- Assessment of farming practices, and social and cultural behaviour that could have an impact on the environment.

- Establish the knowledge base consisting of the domain knowledge (catchment protection/community involvement) and local knowledge (generated from the community meetings).

\section{Stage 3: Awareness creation}

Rural communities in developing countries have lived for centuries in close harmony with their environment. However, due to a variety of reasons including drastic increases in population, limited availability of agricultural land and inefficient agricultural practices, the situation in many countries has changed over the years. Many of these communities now have a continuous struggle to provide sufficient food for survival. The effect thereof is that the harmony between people and the environment has disappeared and that the environment is exploited to supply basic survival needs. This means that these communities are not aware of the damage they cause to the environment and the negative effects thereof on their struggle for survival. In order to change the situation the first step is to make people again aware of how dependent they are on the environment, how their activities affect water quality and how this in turn affects production.

The following activities can assist with awareness creation:

- Carry out initial awareness campaigns informing the community about the need to protect the environment and specifically their water resources, which must be regarded as the lifeblood of food production and survival. Explain the effects of deteriorating water quality on easily understandable matters such as decreasing fish populations and irrigation problems.

- Conduct information sessions about the negative effects of poor farming practices. Indicate the obvious damages caused by erosion, siltation and deforestation. Explain the interactions between overgrazing, cutting down of trees, destroying wetlands and poor crop yields and deteriorating water quality.

- Conduct public workshops and meetings at the lowest possible level throughout the catchment of concern. Public awareness programmes should be continuous so that more and more people become aware of the catchment effort.

\section{Stage 4: Empowerment}

Awareness creation must be followed by empowerment of the community, specifically the farmers. Empowerment must focus on providing information on alternative approaches and alternative farming methods and on how these methods will affect their situation. Training must be provided on the alternative methods. Support must be made available to the farmers in the form of advice on issues such as crop selection and crop rotation, fertilizer needs and application rates and times, and efficient irrigation methods.

- Train individuals from the local community as trainers to create a core of knowledgeable people around whom the programme can be developed and implemented. This also takes advantage of peer-to-peer communication.

- Conduct training sessions on all the different aspects that form the core of the programme. It is critical that these training sessions must be conducted at a level and pace that is appropriate for the people involved. Specialist advice may be required for the development of these programmes to ensure that they are effective.

\section{Stage 5: Implement programme}

Community participation is imperative for the success of the programme because once they identify with the programme they will be interested to see it succeed. The following must form the basis of the strategy:

- Network with other relevant agents like the institutions responsible for the environment, agriculture and forestry. Obtain their commitment for the programme.

- Assign specific duties to community members, such as organising the meetings, taking part in the training, and following up on agreed programmes. People should be committed to certain actions within given periods.

- Assist farmers to optimise their inputs (fertiliser and biocides) for best crop yields. Analysis of soil samples and providing advice is a practical demonstration to the farmers that the programme has their interests at heart.

- Conduct practical field demonstrations of the new methods and encourage action and reflection.

- Attach economic values to the environmental effects for the communities to appreciate what they eventually lose if they do not conserve the resources.

- Develop mechanisms to handle economic and political issues by:

- Making the programme apolitical. Present the project as a purely developmental project aiming at preserving the natural resources and improving farming yields and the quality of life of the community.

- Making the programme self-sustaining by transferring funds from water use and wastewater discharge levies to the ward water associations.

- Obtaining funding from appropriate government departments or donors for community projects like market gardening and poultry projects, which can then generate funds for rehabilitation programmes.

- Creating partnerships between the community and organisations and business concerns. 


\section{Stage 6: Monitor progress and review strategy}

It is important to monitor the changes that are implemented and to measure the effects thereof on the environment and farming yields. It is relatively easy to monitor water quality, but it is not always possible to link changes in water quality to specific activities. The effects of non-controllable changes such as climate (floods, droughts), political influences, etc must be taken into account before conclusions are made. It is equally important to give feedback to the community on the effects of the changes and to indicate how this affects their everyday life. If there is no tangible improvement, the project will not be sustainable. The following measures can be used:

- Agree with all stakeholders on the factors to be used to measure progress. The measures may include water quality analysis, fertiliser application rates, crop yields, extent of re-vegetation, and amount of erosion protection measures put in place.

- Establish a water quality monitoring network (if not already established to measure baseline conditions) and decide on sampling rates, parameters to be analysed and where and by whom analyses are to be done. This should be done with the full participation of the community.

- Establish a programme of collecting hydrological data by:

- Gauging stations if they are available,

- Using alternative means to generate flows like the Velocity Area method and use of models like ACRU.

- Establish a surveillance programme to determine annual fertilizer and farm manure application rates and annual crop yields.

- Communicate the progress of the project to the community during meetings and by using information brochures and circulars. Information dissemination has to be continuous to keep the momentum of the programme and to keep the communities abreast with all events.

- Conduct periodic project reviews and take corrective action if required.

\section{Conclusions}

Water quality management in rural areas of developing countries is a major challenge. In general communal farmers have a culture of concentrating on their immediate survival needs with little regard for the impacts thereof on the environment, specifically water quality. The protocol described in this paper is an attempt to facilitate diffuse water pollution control and protection of the environment in general. The project from which the protocol was derived involved making communities aware of the effects of existing farming practices on the environment, empowerment and training in alternative practices, implementation and monitoring of the effects of changes on water quality and on other environmental aspects.

The approach emphasised stakeholder participation to the extent of giving the communities the opportunity to determine their own destiny and to play a role in the overall water resources management programme. People must be sufficiently empowered to plan and implement their own programmes on a sustainable basis by giving them a sense of ownership of the programme.

In spite of a difficult political climate and adverse climatic conditions, the project has yielded positive initial results. Since the project has been running for only four years, results must be regarded as preliminary at this stage. Sustainability will only be confirmed after a much longer period. It has been adequately demonstrated that the community's awareness has been raised and they have already taken steps to institute the outcomes of the community meetings. Environmental improvements may be obscured by the year-by-year variability in climate and in other factors, making it difficult to discern changes in water quality as a result of the project at this early stage (Stow, 2001; Joelsson and Kyllmar, 2002).

\section{References}

HOFFMANN J R (1994) Non-point Source Pollution in the Hennops River Valley. Water Research Commission Report No. 518/1/95.

JOELSSON A and KYLLMAR K (2002) Implementation of best management practices in agriculture: modelling and monitoring of impacts on nitrogen leaching. Water Sci. Technol. 45 (9).

MARTIN P (1991) Environmental care in agricultural catchments: Towards the communicative catchment. Environ. Manage. 15 (3) 773-783.

MTETWA S and SCHUTTE CF (2002) An interactive and participative approach to water quality management in agro-rural watersheds. Water SA. 28 (3).

NOVOTNY V (1999) Integrating diffuse/non-point pollution control and water body restoration into watershed management. J. Am. Water Works Assoc. 35 (4) 717- 727.

ONGLEY E (1998) Modernisation of water quality programmes in developing countries: issues of relevancy and cost efficiency. Water Qual. Int. (September/October).

SCHOEMAN G (1997) The Development Of Programmes To Combat Diffuse Sources Of Water Pollution In Residential Areas Of Developing Communities. Report to the Water Research Commission, South Africa. WRC Report No 519/1/97.

STOW CA, BORSUK ME and STANLEY DW (2001) Long-term changes in watershed nutrient inputs and riverine exports in the Neuse river, North Carolina. Water Res. 35 (6) 1489-1499.

VAN DER VOORDEN C (2002) The Alfred NZO District Municipality A case study in institutionalising community management. Proceedings of the Biannual Conference of the Water Institute of Southern Africa (WISA), Durban South Africa, May 2002.

WRIGHT EA (2000) Towards a new curriculum for collaborative masters programme: - A systems approach. Paper presented at WARFSA/ WATERNET Symp. on Sustainable Use of Water Resources, Maputo, Mozambique. 
